\title{
SCO YOUTH COOPERATION PROJECTS
}

Vitaly Zolochevsky, Deputy of the State Duma of the Federal Assembly of the Russian Federation, member of SCO Youth Council.

\section{Summary}

The paper provides the examples of some big-scale events held in Russia within the framework of SCO Youth Council, the story is followed by discussion how to improve the work of youth public organizations.

Key words: youth policy, festival, round table, youth organizations.

\section{M.A. MAKAPOB}

\section{ПЕРСПЕКТИВЫ УГЛУБЛЕНИЯ СОТРУДНИЧЕСТВА ПО ВОПРОСАМ ОКРУЖАЮЩЕЙ СРЕДЫ В РАМКАК ШОС}

\author{
Иеорь Алексеевич Макаров, научный сотрудник Центра комплексных \\ европейских и международных исследований НИУ «Высшая школа экономики».
}

\begin{abstract}
Аннотация
Автор обосновывает необходимость экологического сотрудничества в рамках ШОС на базе концепции «зеленого экономического роста». Подчеркивается, что экологические проблемы в странах ШІОС (особенно в Китае) превращаются из национальных в региональные. Рассмотрены конкретные направления возможннгг экологического сотрудничества: регулирование использования водных ресурсов, координация систем торговли выбросами на выбросы парниковых газов, гармонизация экологических стандартов и обмен зелеными технологиями. ШОС, по мнению автора, имеет потенциал стать главной площадкой разрешения экологических конфликтов в регионе.
\end{abstract}

Ключевые слова: экология, природопользование, структура производства, водные ресурсы, парниковые газы, торговля квотами, зеленые технологии.

Современный этап развития мировой экономки и международных отношений характеризуется ростом интереса к ресурсным и экологическим проблемам. Это связано с рядом факторов: усилением волатильности цен на топливное и минеральное сырье, увеличивающейся нехваткой многих видов невозобновляемых природных ресурсов (пресной воды, пахотной земли, рыбных, лесных ресурсов); ростом реального ущерба от экологических проблем, приобретением все большим их количеством трансграничного характера.

Проблемы окружающей среды в настоящее время нередко рассматриваются в качестве угрозы национальной безопасности; обеспечение экологической безопасности все чаще объявляется в качестве приоритета государственной политики той или иной страны.

Во многих странах становится модным ставить под сомнение объективность и полноту ВВП как индикатора национального богатства. Растет внимание к качеству экономи- 
ческого роста, которое зависит во многом от неденежных компонентов благосостояния: здоровья, благоприятной окружающей среды, доступа к достойному питанию и пресной воде. Более того, сформировалось понимание, что решение экологических проблем не является препятствием росту ВВП, а иногда даже стимулирует его. Теоретическим обоснованием этого является концепция «зеленого экономического роста», которая уже активно реализуется на практике рядом развитых и развивающихся государств.

Зачем нужно экологическое сотрудничество в рамках ШОС?

Согласно Хартии ШОС, среди целей организации - поощрение эффективного регионального сотрудничества в природоохранной области. А «обеспечение рационального природопользования, включая использование водных ресурсов в регионе, осуществление совместных специальных природоохранных программ и проектов» входит в число основных направлений функционирования Организации. Вместе с тем реальные шаги по развитию экологического сотрудничества в рамках ШОС до сих пор оставались относительно скромными. По ключевому направлению сотрудничества - в области поддержания безопасности - основное внимание традиционно уделялось традиционным угрозам, вопросы экологической безопасности поднимались с осторожностью и лишь на уровне общих деклараций. Однако в настоящее время появился ряд предпосылок, которые могут вывести вопросы экологического сотрудничества на видное место в совместной повестке.

Во-первых, вопросам окружающей среды уделяется все большее внимание в Китае. Борьба с экологическими проблемами вошла в число приоритетов Двенадцатого пятилетнего плана и будет занимать еше более заметное место в Тринадцатом. На уровне первых лиц страны признается колоссальный ущерб от экологических проблем: по официальным данным, по некоторым провинциям он доходит до $13 \%$ ВВП. Особенно болезненно воспринимаются экологические проблемы крупнейших городов, где население по мере роста дохода предъявляет растуший спрос на благоприятную экологическую обстановку. По мере того как экологическая повестка занимает все более заметное место внутри Китая, растет и готовность обсуждать экологические инициативы с другими государствами.

Во-вторых, все отчетливее наблюдается тенденция постепенного переноса трудоемких и энергоемких производств из Китая в другие азиатские страны, где издержки на производство продукции ниже, в первую очередь в Юго-Восточную Азию, Монголию и Центральную Азию. Это означает, что экологические проблемы соседних с Китаем стран, которые воспринимались им как внешние, а потому не заслуживающие пристального внимания, постепенно становятся для него важными. Особенно это касается проблемы водных ресурсов. По мере того, как в странах, расположенных ниже по течению Меконга и Черного Иртыша, будут разворачиваться китайские производства, Китай вынужден будет учитывать интересы этих стран во все большей степени.

Другая тенденция связана с переносом Китаем в страны Юго-Восточной и Центральной Азии наиболее экологически грязных производств с целью смягчения внутренних проблем окружающей среды. Этот процесс неизбежно приведет к переходу экологической повестки с национального на региональный уровень, и страны демонстрируют к этому возрастающую готовность.

В-третьих, сама Шанхайская организация сотрудничества, видимо, в ближайшие годы будет стремиться к еще большему развитию экономического сотрудничества, в сферу которого преимущественно и попадают на сегодня проблемы экологического регулирования. В ведущих странах на смену административным инструментам (технологическим стандартам или обязательным нормативам) экологической политики давно пришли рыночные механизмы: ценовые (налоги или субсидии) и количественные (системы распределения квот и торговли квотами на выбросы/загрязнения). Постепенно рыночные инструменты регулирования внедряются и в странах ШОС, в первую очередь в Китае и Казахстане. Практика применения подобных инструментов в развитых странах проде- 
монстрировала, что их использование различными странами крайне эффективно и относительно легко координировать. В азиатском регионе одной из таких координирующих площадок может являться ШОС.

Развитие международного сотрудничества по вопросам окружающей среды в рамках ШОС может осуществляться по следующим направлениям:

1. Регулирование использования водных ресурсов. На территории стран - членов ШОС расположены трансграничные бассейны рек Обь и Иртыш, Амударья и Сырдарья. Отсутствие бассейнового регулирования, устанавливающего четкие правила забора воды исходя из интересов устойчивого развития, может иметь далеко идущие последствия, связанные с опустыниванием территорий, гибелью экосистем, значительным ущербом для экономической деятельности. Плодом нерационального использования рек Амударья и Сырдарья уже стала экологическая катастрофа в Аральском море, а растуший забор воды из Черного Иртыша постепенно приводит к аридизации обширных территорий Казахстана и дефициту воды в Оби в России.

Использование каждого из этих бассейнов характеризуется конфликтом интересов стран, расположенных в верховьях и низовьях. Этот конфликт в каждом из случаев имеет объективный характер. Так, в случае с Черным Иртышом растущий забор воды объясняется экономическим ростом в регионе и необходимостью снабжать увеличивающееся население все большим количеством пресной воды и продовольствия. В ситуации с Амударьей и Сырдарьей Таджикистану и Киргизии, контролирующим 2/3 стока этих рек, вода остро необходима для энергетических нужд.

Страны верховья до сих пор предпочитают называть проблему излишнего водозабора внутренней, но интенсификация экономического сотрудничества в регионе, которая будет происходить в ближайшее время, неизбежно заставит начать диалог по водному вопросу. С учетом того, что нехватка воды является реальной угрозой безопасности стран низовий, одной из площадок для такого диалога может стать ШОС. Ключевой задачей является реализация интегрированного подхода к управлению водными ресурсами в рамках каждого из бассейнов. Такой подход предполагает планирование водозабора и загрязнений исходя из целей устойчивого использования водных ресурсов и недопущения экологических катастроф.

Для смягчения водных конфликтов при условии реализации интегрированного подхода в регионе может быть выстроена система торговли водоемкой продукцией (виртуальной водой), при которой она будет производиться в водообеспеченных странах и регионах и импортироваться в вододефицитные. Это позволит последним сократить потребление собственных водных ресурсов.

2. Координация систем торговли квотами на выбросы парниковых газов. В регулировании выбросов парниковых газов наиболее популярным в настоящее время инструментом государственной политики являются системы торговли квотами (cap-and-trade), предполагающие установление потолка выбросов для конкретной территории, распределение между базирующимися на ней компаниями разрешений на выбросы и возможность торговать ими. Системы торговли квотами уже появились (на наднациональном, национальном или региональном уровне) в большинстве развитых государств и постепенно появляются в развивающихся. В Казахстане система торговли квотами на выбросы парниковых газов введена в 2013 г., а в Китае реализуются шесть пилотных схем на уровне провинций с дальнейшими планами перехода к общенациональной системе торговли квотами. Рыночные инструменты регулирования выбросов парниковых газов (система торговли квотами является наиболее вероятным вариантом) планируется ввести и в России, правда, скорее всего, после 2020 г.

Расширение количества систем торговли квотами в мире остро ставит вопрос об их координации. Уже объявлено о будущем слиянии рынков разрешений на выбросы ЕС и Австралии, Калифорнии и канадской провинции Онтарио. Слияние однородных рынков выгодно компаниям, так как при прочих равных снижает цены на разрешения, 
а следовательно, издержки предприятий. Если в России будет создана система торговли квотами, то ее постепенное слияние с казахстанской в условиях наличия ЕАЭС практически неизбежно. В дальнейшем же возможно расширение этого рынка и на Китай, на первых порах - с некоторыми ограничениями.

В эту схему взаимодействия национальных систем торговли квотами крупнейших стран ШОС могут гармонично встроиться и страны Центральной Азии. Эти страны особенно уязвимы перед лицом изменения климата. Россия в рамках международных переговоров по климатическому соглашению изъявила готовность выступать в качестве страны-донора климатической помощи по отношению к центрально-азиатским республикам. Эта помощь может оказываться в формате осуществления компаниями инвестиционных проектов, связанных с сокращением выбросов, в счет своих обязательств. Такая схема - это аналог того, как механизм чистого развития был встроен в европейскую систему торговли квотами.

3. Гармонизация экологических стандартов и обмен зелеными технологиями. В 2012 г. на саммите АТЭС во Владивостоке странами-участницами была достигнута договоренность о снижении тарифов на экологические товары. Аналогичная (или даже более серьезная - вплоть до снижения тарифов до нуля) мера могла бы быть принята и в рамках ШОС. Это способствовало бы ускоренному распространению «зеленых» технологий и «зеленых» поведенческих практик в государствах-членах. Одновременно была бы полезна гармонизация законодательства стран в части выполнения экологических требований, а также унификация экологических стандартов.

Несмотря на то, что экологическое сотрудничество изначально обозначалось в качестве одного из приоритетных направлений функционирования ШОС, реальные масштабы кооперации по вопросам окружающей среды были достаточно скромными. Однако в настоящее время экологическая повестка может занять одно из ведущих мест в деятельности ШОС. Это связано как с нацеленностью государств на углубление экономического сотрудничества (которое вбирает в себя многие вопросы экологического регулирования), так и с новым взглядом на экологические проблемы в Китае. ШОС на сегодняшний день - главная в регионе площадка, имеющая потенциал эффективного разрешения экологических конфликтов, а также способная запускать совместные экологические инициативы. И то, и другое критически необходимо в связи с возрастающими масштабами экологических проблем в странах-членах.

\section{PERSPECTIVES FOR THE DEEPENING OF COOPERATION ON ENVIRONMENTAL PROBLEMS WITHIN SCO STRUCTURE}

Igor Makarov, Research fellow, Center for Comprehensive International and European Studies, NRU Higher School of Economics.

\section{Summary}

The author argues for necessity of ecological cooperation within SCO, it should be based on the concept of "green economic growth". He notes that in SCO countries (especially in China) ecological problems are being transformed from national to regional. Under consideration are the directions of possible ecological cooperation: water resources management, coordination of trading of quotas for greenhouse emissions, harmonization of ecological standards and exchange of green technologies SCO has the potential of becoming the main platform of solving ecological disputes in the region.

Key words: ecology, nature management, structure of production, water resources, greenhouse emissions, quota trading, green technologies. 